\title{
A study of anaesthesia-related cardiac arrest from a Chinese tertiary hospital
}

\author{
Chu-Lian Gong ${ }^{\dagger}$, Jing-Ping Hư ${ }^{\dagger}$, Zhuo-Lin Qiu, Qian-Qian Zhu, Zi-Qing Hei, Shao-Li Zhou* and Xiang Li ${ }^{*}$ (D)
}

\begin{abstract}
Background: The present survey evaluated the incidence of perioperative cardiac arrests in a Chinese tertiary general teaching hospital over ten years.

Methods: The incidence of cardiac arrest that occurred within $24 \mathrm{~h}$ of anaesthesia administration was retrospectively identified in the Third Affiliated Hospital of Sun Yat-Sen University between August 2007 and October 2017. Overall, 152,513 anaesthetics were included in the study period. Data collected included patient characteristics, American Society of Anaesthesiologists (ASA) physical status score, surgical specialty and anaesthesia technique. Cardiac arrests were assigned to one of three groups: "anaesthesia-related", "anaesthesia-contributing" or "anaesthesia-unrelated".

Results: In total, 104 cardiac arrests (6.8:10,000) and 34 deaths (2.2:10,000) were obtained. Among them, eleven cardiac arrests events were anaesthesia-related, resulting in an incidence of 0.7 per 10,000 anaesthetics. Sixteen cardiac arrests events were found to be anaesthesia-contributing, resulting in an incidence of 1.0 per 10,000 anaesthetics. Cardiovascular adverse events were the major events that contributed to anaesthesia-related cardiac arrest. Differences were found between events related and unrelated to anaesthesia with regard to ASA physical status and anaesthesia technique $(P<0.05)$.

Conclusions: Anaesthesia-related cardiac arrest occurred in 11 of 104 cardiac arrests within $24 \mathrm{~h}$ of anaesthesia administration. Most cardiac arrests related to anaesthesia were due to cardiovascular events, including arrhythmia and hypotension after intravenous narcotic, as well as haemorrhage. ASA physical status of at least 3 and subarachnoid block appeared to be relevant risk factors for anaesthesia-related cardiac arrest.
\end{abstract}

Keywords: Anaesthesia, Cardiac arrest, Incidence

\section{Background}

Since 2012, more than 310 million major surgical procedures have been performed annually worldwide [1]. Perioperative cardiac arrest is a rare but potentially catastrophic event that is associated with high mortality. An overall perioperative cardiac arrest rate of 7.19/10,000 anaesthetics was reported worldwide from the 1990s to the 2000s [2]. In recent decades, several studies have described the incidence and causes of postoperative cardiac arrest related to anaesthesia in different patient populations from different countries, such as the United States [3], Germany [4], France [5], Pakistan [6], Saudi Arabia [7], and Brazil [8].

\footnotetext{
* Correspondence: lixiang86-26@163.com; shaolizhou@139.com ${ }^{\dagger}$ Chu-Lian Gong and Jing-Ping Hu contributed equally to this work. Department of Anesthesiology, The Third Affiliated Hospital of Sun Yat-sen University, Guangzhou, People's Republic of China
}

Although more than $10 \%$ of major surgical procedures worldwide are performed in China [1], there is limited information available on the incidence of anaesthesia-related cardiac arrest and risk factors for perioperative cardiac arrest in Chinese tertiary hospitals. Most Chinese publications regarding anaesthesia-related cardiac arrest are published in Chinese journals that are not indexed by the global databases. A multicentre prospective survey, including 106,569 patients from eleven Chinese teaching hospitals, found the incidence of cardiac arrest for patients undergoing regional anaesthesia to be $0.09 / 10,000$ [9]. However, studies on perioperative cardiac arrest for large unselected patient populations are still lacking. As the incidence of cardiac attest within the $24 \mathrm{~h}$ perioperative period is an important component of the anaesthesia quality control index system published by the National Health and Family Planning Commission of the People's Republic

(c) The Author(s). 2018 Open Access This article is distributed under the terms of the Creative Commons Attribution 4.0 International License (http://creativecommons.org/licenses/by/4.0/), which permits unrestricted use, distribution, and 
of China in 2015, we sought to assess the incidence and risk factors for anaesthesia-related cardiac arrest within the $24 \mathrm{~h}$ perioperative period in a Chinese tertiary care university hospital.

\section{Methods}

This project was approved by the Research Ethics Committee of the Third Affiliated Hospital of Sun Yat-sen University (Ref: [2017] 2-216). Because of the retrospective and anonymous nature of this study, written informed consent was waived by the Research Ethics Committee of the Third Affiliated Hospital of Sun Yat-sen University. We retrospectively analysed data from critical incident reports of our Department of Anaesthesiology from 152,513 anaesthesiological procedures at the Third Affiliated Hospital of Sun Yat-sen University from August 2007 to October 2017.

The Third Affiliated Hospital of Sun Yat-sen University, which was founded in 1971, is an 1800-bed public tertiary teaching hospital performing more than 15,000 surgeries per year to all ages and provides care to the population of Guangdong province and the surrounding areas. In our department, it is mandatory to record critical incidents, including cardiac arrest, that occur within $24 \mathrm{~h}$ of anaesthesia administration in an anaesthesia database. This record is compiled and completed by the anaesthesia team involved in the anaesthetic case.

In accordance with previous studies $[3,4,8]$, cardiac arrest was defined as an event requiring cardiopulmonary resuscitation, which might involve closed- or open-chest compressions.

According to the classification system from Hohn et al. [4], all cardiac arrest events were assigned to one of three groups based on the contributory factor that caused the cardiac arrest: anaesthesia-related group (anaesthesia was the only or major contributing factors); anaesthesia-contributing group (both surgery and anaesthesia were the contributing factors or there was some doubt whether cardiac arrest was entirely attributable to anaesthesia); and anaesthesia-unrelated group (surgery or other factors were the contributing factors) (Table 1).

For each cardiac arrest case, basic characteristics of the patient (name, age, sex); surgical procedures (elective, urgent or emergency surgery) and area; American Society of Anaesthesiologists (ASA) physical status classification; anaesthetic technique (general anaesthesia, regional anaesthesia including epidural/spinal/caudal or plexus block, sedation); and a checklist of airway, respiratory, cardiocirculatory, neurological, renal and miscellaneous events were obtained.

To avoid a potential incomplete case collection, the anaesthesia team that was responsible for each cardiac arrest event was asked to review the case and provide a written summary and presentation for peer review. The cardiac arrest commission of the Department of Anaesthesiology at the Third Affiliated Hospital of Sun Yat-sen University, which was composed of three senior anaesthesiologists, analysed the anaesthesia and medical records, critical incident report form, written summary and presentation for each cardiac arrest event. Disagreements on the cause of cardiac arrest were resolved by discussion among the three members, and agreement or consensus was determined when at least two out of three members agreed on the event cause.

The primary adverse events leading to cardiac arrest that occurred within $24 \mathrm{~h}$ of anaesthesia administration were grouped into the following categories, as proposed by Cheney et al.: respiratory (difficult intubation, inadequate ventilation/oxygenation, oesophageal intubation, premature extubation, aspiration, airway obstruction, endobronchial intubation, bronchospasm, and inadvertent extubation), cardiovascular (multifactorial/miscellaneous events, pulmonary embolism, inadequate fluid therapy, stroke, haemorrhage and myocardial infarction), medication-related, equipment-related, block-related, procedural, iatrogenic and other not further classified incidents [10]. In addition, for the cardiovascular category, arrhythmia and hypotension were involved in multifactorial/

Table 1 Classification system for cardiac arrest [4]

\begin{tabular}{ll}
\hline Group & Definition \\
\hline Anaesthesia-related & $\begin{array}{l}\text { Where it is reasonably certain that CA was caused by the anaesthesia or other factors under the control } \\
\text { of the anaesthetist }\end{array}$ \\
Anaesthesia-contributing & $\begin{array}{l}\text { 1. Where there is some doubt whether CA was entirely attributable to the anaesthesia or other factors } \\
\text { under the control of the anaesthetist } \\
\text { 2. Where CA was caused by both surgical and anaesthesia factors }\end{array}$ \\
$\begin{array}{ll}\text { 1. CA where the administration of the anaesthesia did not contribute and surgical or other factors are } \\
\text { implicated }\end{array}$ \\
$\begin{array}{l}\text { 2. Inevitable CA, which would have occurred irrespective of anaesthesia or surgical procedures } \\
\text { 3. Incidental CA, which could not reasonably be expected to have been foreseen by those looking after } \\
\text { the patient, was not related to the indication for surgery and was not due to factors under the control } \\
\text { of the anaesthetist or surgeon. } \\
\text { 4. Those that cannot be assessed despite considerable data but where the information is conflicting or } \\
\text { key data are missing } \\
\text { 5. Cases that cannot be assessed because of inadequate data }\end{array}$ \\
\end{tabular}


miscellaneous events in circumstances where the primary event leading to cardiovascular system changes was not obvious. Also included in the multifactorial cardiovascular events were surgical complications and patient conditions, including tamponade, and pathologic abnormalities that were undiagnosed before surgery but determined by autopsy, such as congenital abnormalities, viral myocarditis, myocardial fibrosis, and unsuspected severe coronary artery disease [10].

The characteristics of anaesthesia-related or contributed cardiac arrest cases and anaesthesia unrelated cardiac arrest cases were summarized and compared. We used means and SDs for continuous variables and numbers and percentages for categorical variables. The $x^{2}$ test and two independent samples t-test were used to compare categorical and continuous variables, respectively. Statistical analysis for all data was performed using SPSS software (version 20.0, SPSS, Chicago, IL, USA). A $P$ value of less than 0.05 was considered statistically significant.

\section{Results}

Over the 10 years of the study (2007-2017), 152,513 patients received anaesthesia care at the Third Affiliated Hospital of Sun Yat-sen University. Within this time period, 238 patients who underwent surgery experienced cardiac arrest after anaesthesia administration. Among those patients, 104 cardiac arrest events occurred within $24 \mathrm{~h}$ of anaesthesia administration, which meant that the cardiac arrest rate within $24 \mathrm{~h}$ of anaesthesia administration was $6.8 / 10,000$. The overall mortality from cardiac arrest within $24 \mathrm{~h}$ of anaesthesia administration was 44 of 104 cardiac arrest events $(2.9 / 10,000)$. Among 11 patients with cardiac arrest related to anaesthesia, four (36.4\%) did not survive, while for cardiac arrests that contributed to or were unrelated to anaesthesia, six (6/ $16,37.5 \%)$ and $34(34 / 77,44.2 \%)$ patients died, respectively. Figure 1 shows a flow diagram illustrating the review process for identifying cardiac arrest events.

For all 104 patients with cardiac arrest, the median age was 52 years old (range 2 to 96 years old). Only four patients with cardiac arrest were less than 3 years old, while 15 patients were older than 75 years. Males comprised $57.7 \%$ of the cardiac arrest cases (60/104). Forty patients with cardiac arrest were ASA physical status of at least 3, and 25 cardiac arrest patients had a New York Heart Association (NYHA) functional score of at least 3. Fifty-three cardiac arrest patients underwent emergency surgeries. General anaesthesia was the predominant anaesthetic technique used in cases with cardiac arrest.

Patient characteristics and adverse events leading to anaesthesia-related cardiac arrest are shown in Table 2 . There were 11 cardiac arrest events, resulting in a cardiac arrest rate related to anaesthesia of 0.7 per 10,000 anaesthetics. The median age was 50 years old (range 2 to 96 years old). Males comprised $54.5 \%$ of the anaesthesia-related cardiac arrest cases. General anaesthesia was the primary technique. Four patients with

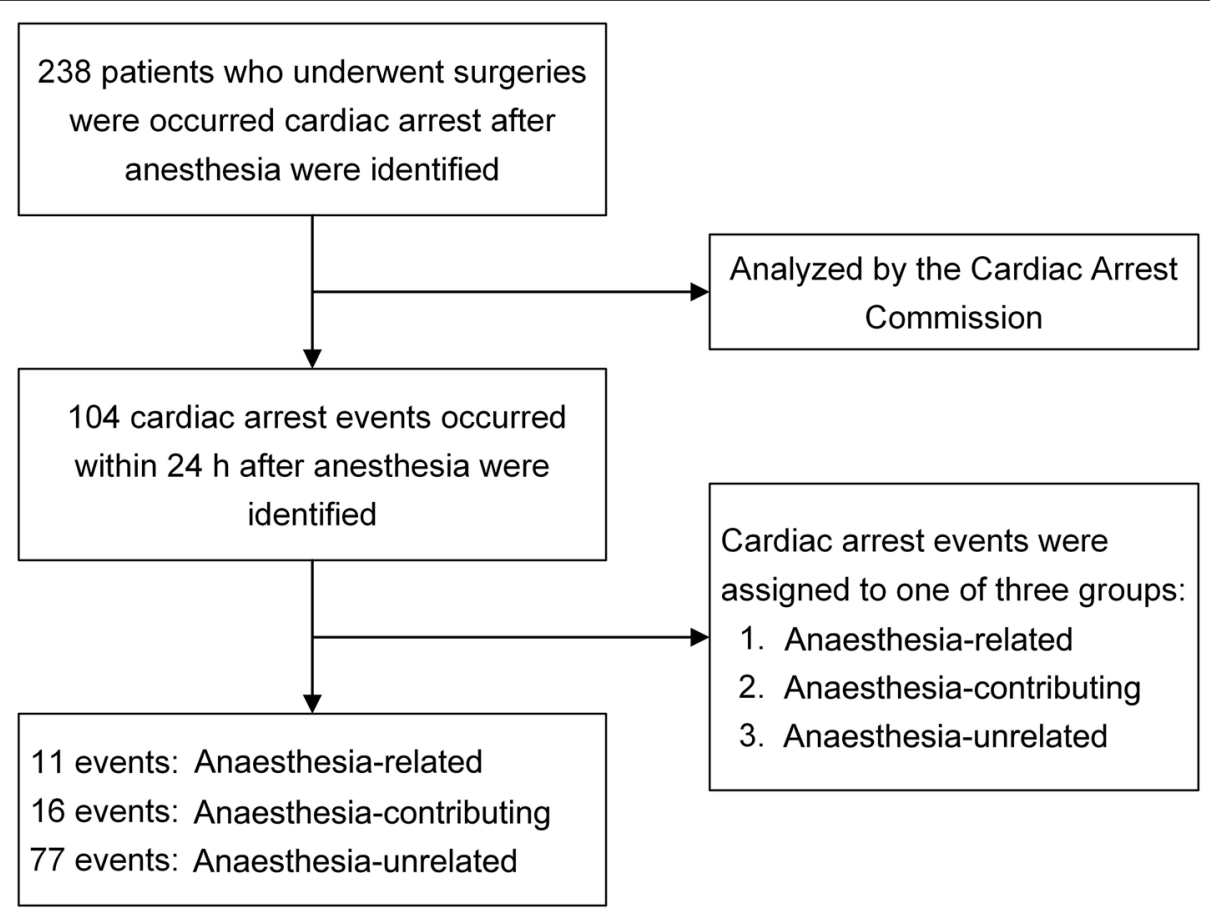

Fig. 1 Flow diagram of review process to identify anaesthesia-related and anaesthesia-contributing cardiac arrest events 
Table 2 Patient characteristics and adverse events leading to anaesthesia-related cardiac arrest $(n=11)$

\begin{tabular}{|c|c|c|c|c|c|c|c|c|c|}
\hline No. & Age range & Sex & NYHA & Speciality & ASA PS & $\begin{array}{l}\text { Anesthesia } \\
\text { Technique }\end{array}$ & Adverse Event Leading to Cardiac Arrest & Category & Outcome \\
\hline 1 & $90-100$ & 1 & III & Orthopedic surgery & IV & GA & $\begin{array}{l}\text { Hypotension and dysrhythmia after } \\
\text { intravenous narcotic. Multiple } \\
\text { comorbidities. }\end{array}$ & Cardiovascular & Recovered \\
\hline 2 & $50-60$ & 2 & I & General surgery & IIIE & GA & $\begin{array}{l}\text { Dysrhythmia due to the use of neophryn } \\
\text { for hypotension and bradycardia during } \\
\text { surgery. }\end{array}$ & Medication & Recovered \\
\hline 3 & $90-100$ & 2 & III & Spinal surgery & III & GA & $\begin{array}{l}\text { Bradycardia and dysrhythmia after } \\
\text { intravenous narcotic. Multiple } \\
\text { comorbidities. }\end{array}$ & Cardiovascular & Died \\
\hline 4 & $30-40$ & 2 & I & Traumatology & IIIE & GA & $\begin{array}{l}\text { Massive aspiration of blood after } \\
\text { induction, hypoxia. }\end{array}$ & Respiratory & Died \\
\hline 5 & $20-30$ & 2 & । & Spinal surgery & । & $S A B$ & $\begin{array}{l}\text { Bradycardia and dysrhythmia after } \\
\text { postural change. }\end{array}$ & Regional block & Recovered \\
\hline No. & Age range & Sex & NYHA & Speciality & ASA PS & $\begin{array}{l}\text { Anesthesia } \\
\text { Technique }\end{array}$ & Adverse Event Leading to Cardiac Arrest & Category & Outcome \\
\hline 6 & $20-30$ & 1 & । & ENT surgery & । & GA & $\begin{array}{l}\text { Loss of airway on PACU due to bleeding } \\
\text { and laryngospasm after nasal trumpet } \\
\text { placed. }\end{array}$ & Respiratory & Recovered \\
\hline 7 & $40-50$ & 2 & $\|$ & Traumatology & IIIE & GA & $\begin{array}{l}\text { Intraperitoneal hemorrhage, cardiac arrest } \\
\text { during insertion of central venous catheter. }\end{array}$ & Cardiovascular & Died \\
\hline 8 & $30-40$ & 1 & । & General surgery & । & $S A B$ & $\begin{array}{l}\text { Bradycardia and dysrhythmia } 15 \text { min after } \\
\text { the block. }\end{array}$ & Regional block & Recovered \\
\hline 9 & $80-90$ & 1 & III & Orthopedic surgery & IV & GA & $\begin{array}{l}\text { Hypotension and acute myocardial ischemia } \\
\text { after intravenous narcotic. Multiple } \\
\text { comorbidities. }\end{array}$ & Cardiovascular & Died \\
\hline 10 & $70-80$ & 1 & $\|$ & Orthopedic surgery & III & $S A B$ & $\begin{array}{l}\text { Seizure and dysrhythmia due to the local } \\
\text { anesthetic intoxation. }\end{array}$ & Medication & Recovered \\
\hline 11 & $0-10$ & 1 & I & ENT surgery & I & GA & $\begin{array}{l}\text { Displacement of endotracheal tubes during } \\
\text { surgery. A failure to ventilate and intubate. } \\
\text { Problem with fixation of the tracheal tube. }\end{array}$ & Respiratory & Recovered \\
\hline
\end{tabular}

NYHA New York Heart Association, ASA PS American Society of Anesthesiologists physical status score, GA general anesthesia, SAB subarachnoid block, PACU postanesthesia care unit

anaesthesia-related cardiac arrest died (36.4\%), which meant a mortality rate of $0.3 / 10,000$. Cardiovascular adverse events were the major events contributing to cardiac arrest $(n=4)$, which comprised $36.4 \%$ of the cases. Among these four cases, three of the patients were older than 85 years. In addition, medication, respiratory and regional block-related adverse events comprised the remaining cases.

Table 3 shows the patient characteristics and adverse events leading to anaesthesia-contributing cardiac arrest. The number of anaesthesia-contributing cardiac arrests was 16 , which is a rate of $1.0 / 10,000$. Six patients (37.5\%) with anaesthesia-contributing cardiac arrest died, which meant a mortality rate of $0.4 / 10,000$. The median age was 55 years old (range 3 to 86 years old). Males comprised $56.3 \%$ of the anaesthesia-related cardiac arrest cases. The majority of patients $(75.0 \%, 12 / 16)$ suffered from cardiac arrest due to cardiovascular complications, which included myocardial infarction, hypotension, ST segment depression, bradycardia and ventricular fibrillation. There were three cases $(18.8 \%)$ of respiratory complications, all of which had a cardiac arrest after arrival in the intensive care unit (ICU) or post-anaesthesia care unit (PACU).

As the four paediatric patients occupied a small number of the 104 patients undergoing cardiac arrest within $24 \mathrm{~h}$ of anaesthesia administration, the univariate analyses for risk factors were only performed on adult patients. Differences were found between events related and unrelated to anaesthesia with regard to ASA physical status and anaesthesia technique (Table 4 , all $P<$ $0.05)$, while no differences were found between events contributing to and unrelated to anaesthesia (Table 5).

\section{Discussion}

During the perioperative period, cardiac arrest and death always represent the worst patient outcomes and are still the most severe challenges for anaesthetists. From the 1990 s to the 2000s, the global incidences of perioperative cardiac arrest ranged from 6.59/10,000 anaesthetics in highly developed countries to $20.68 / 10000$ in less-developed countries [2]. In the last decades, China 


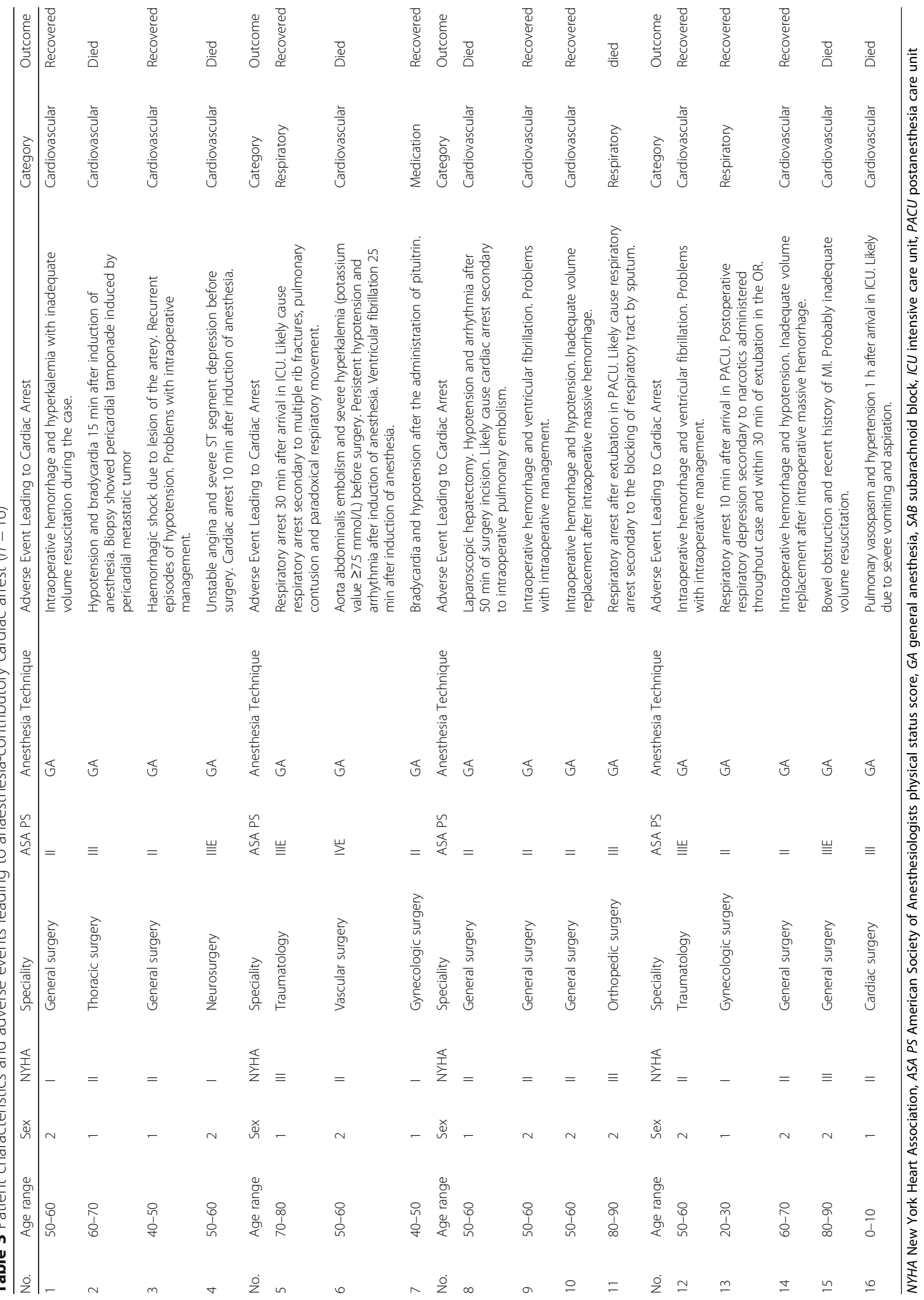


Table 4 Univariate analysis for risk factors of adult patients with anaesthesia-related cardiac arrest

\begin{tabular}{|c|c|c|c|c|c|}
\hline \multirow[t]{2}{*}{ Terms } & \multicolumn{2}{|c|}{ Anaesthesia related to cardiac arrest } & \multicolumn{2}{|c|}{ Anaesthesia unrelated to cardiac arrest } & \multirow[t]{2}{*}{$P$} \\
\hline & $\mathrm{n}$ & Mean \pm SD or percentage & $\bar{n}$ & Mean \pm SD or percentage & \\
\hline Age $(y r)$ & 10 & $56.5 \pm 28.3$ & 75 & $53.2 \pm 17.4$ & 0.725 \\
\hline Mortality & 4 & $40.0 \%$ & 34 & $45.3 \%$ & 0.750 \\
\hline Sex & & & & & 0.936 \\
\hline Male & 6 & $60.0 \%$ & 44 & $58.7 \%$ & \\
\hline Female & 4 & $40.0 \%$ & 31 & $41.3 \%$ & \\
\hline ASA PS & & & & & 0.019 \\
\hline$<3$ & 3 & $30.0 \%$ & 51 & $68.0 \%$ & \\
\hline$\geq 3$ & 7 & $70.0 \%$ & 24 & $32.0 \%$ & \\
\hline NYHA & & & & & 0.752 \\
\hline$<3$ & 7 & $70.0 \%$ & 56 & $74.7 \%$ & \\
\hline$\geq 3$ & 3 & $30.0 \%$ & 19 & $25.3 \%$ & \\
\hline Anaesthesia technique & & & & & 0.008 \\
\hline GA & 7 & $70.0 \%$ & 71 & $94.7 \%$ & \\
\hline$S A B$ & 3 & $30.0 \%$ & 4 & $5.3 \%$ & \\
\hline Surgical characteristics & & & & & 0.492 \\
\hline Emergency & 3 & $30.0 \%$ & 44 & $58.7 \%$ & \\
\hline Non-Emergency & 7 & $70.0 \%$ & 31 & $41.3 \%$ & \\
\hline
\end{tabular}

ASA PS American Society of Anaesthesiologists physical status score, NYHA New York Heart Association, GA general anaesthesia, SAB subarachnoid block

Table 5 Univariate Analysis for risk factors of adult patients with anaesthesia-contributing cardiac arrest

\begin{tabular}{|c|c|c|c|c|c|}
\hline \multirow[t]{2}{*}{ Terms } & \multicolumn{2}{|c|}{ Anaesthesia contributing to cardiac arrest } & \multicolumn{2}{|c|}{ Anaesthesia unrelated to cardiac arrest } & \multirow[t]{2}{*}{$P$} \\
\hline & $\mathrm{n}$ & Mean \pm SD or percentage & $n$ & Mean \pm SD or percentage & \\
\hline Age (yr) & 15 & $58.3 \pm 15.5$ & 75 & $53.2 \pm 17.4$ & 0.290 \\
\hline Mortality & 6 & $40.0 \%$ & 34 & $45.3 \%$ & 0.704 \\
\hline Sex & & & & & 0.924 \\
\hline Male & 9 & $60.0 \%$ & 44 & $58.7 \%$ & \\
\hline Female & 6 & $40.0 \%$ & 31 & $41.3 \%$ & \\
\hline ASA PS & & & & & 0.275 \\
\hline$<3$ & 8 & $53.3 \%$ & 51 & $68.0 \%$ & \\
\hline$\geq 3$ & 7 & $46.7 \%$ & 24 & $32.0 \%$ & \\
\hline NYHA & & & & & 0.661 \\
\hline$<3$ & 12 & $80.0 \%$ & 56 & $74.7 \%$ & \\
\hline$\geq 3$ & 3 & $20.0 \%$ & 19 & $25.3 \%$ & \\
\hline Anaesthesia technique & & & & & 0.360 \\
\hline GA & 15 & $100.0 \%$ & 71 & $94.7 \%$ & \\
\hline$S A B$ & 0 & $0.0 \%$ & 4 & $5.3 \%$ & \\
\hline Surgical characteristics & & & & & 0.072 \\
\hline Emergency & 5 & $33.3 \%$ & 44 & $58.7 \%$ & \\
\hline Non-Emergency & 10 & $66.7 \%$ & 31 & $41.3 \%$ & \\
\hline
\end{tabular}


has experienced significant improvements in economic and human indicators, thereby decreasing the inequality in relation to countries with very high human development. The present study reported comparable incidences of overall and anaesthesia-related cardiac arrests in a Chinese tertiary hospital over a ten-year period (20072017) to high human development countries (according to the Human Development Index (HDI) set by the United Nations Development Programme), such as the United States [3], Germany [4] and Brazil [11].

The adverse events leading to anaesthesia-related cardiac arrest differ among various studies. Although the respiratory and airway-related adverse events are considered the major reasons for anaesthesia-related fatal outcomes (death, cardiac arrest) $[3,4]$, this has not been consistent for all studies. The rates of anaesthesia-related death resulting from airway management events have ranged widely from 7.9 to $80 \%$ [12]. A study based on data from the Pediatric Perioperative Cardiac Arrest Registry revealed that cardiovascular events, including hypovolaemia from blood loss and hyperkalaemia from transfusion of stored blood, were the most common causes for anaesthesia-related cardiac arrest (41\% of all cardiac arrest patients) [13]. In the present study, cardiovascular events and problems were also the primary cause of anaesthesia-related cardiac arrest (36.4\% of all anaesthesia-related cardiac arrest patients), and respiratory, medication and regional block accounted for the rest of the events. Some analyses have demonstrated that the predominance of cardiovascular events in anaesthesiarelated cardiac arrest may be associated with the increasing use of respiratory monitors, such as pulse oximetry, capnography, disconnection alarms, and low-pressure alarms, which may be more helpful to prevent respiratory rather than cardiovascular events $[10,11]$. In addition, advances in clinical practices, such as adoption of standardized guidelines for management of difficult airways, might also be helpful for reducing the incidence of cardiac events due to the airway [14].

Most patients experiencing anaesthesia-related cardiac arrest due to cardiovascular events and problems were older than 85 years, and the cardiac arrest occurred after intravenous narcotic. This result was in accordance with the study reported by Nunes et al., who found that two-thirds of anaesthesia-related cardiac arrest events in older patients were also due to cardiovascular collapse after neuroaxial anaesthesia [15]. In this study, three elderly patients had multiple serious cardiovascular comorbidities, including hypertension, coronary heart disease and arrhythmia; thus, they were particularly vulnerable to cardiovascular events, such as persistent hypotension and myocardial infarction due to the neuroaxial anaesthesia. Previous studies have suggested an adequate preoperative evaluation that might be helpful for avoiding the incidence of anaesthesia-related cardiac arrest [16-
18]. Therefore, adopting perioperative medical practices with demonstrable effectiveness, organizing multidisciplinary discussion of adverse effects and implementing evidence-based safety protocols are necessary for preventing anaesthesia-related cardiac arrests in older patients.

Notably, two anaesthesia-related cardiac arrest events were due to regional block problems. Cardiac arrest events during spinal anaesthesia are rare and unexpected but are not uncommon. The incidence of cardiac arrest after spinal anaesthesia and neuraxial blockade was reported to range from 1.3 to 18 per 10,000 anaesthetic [17]. In this study, both of patients were young and healthy, and ropivacaine was used for subarachnoid injection to obtain maximum sensory block up to the T6 level. Two patients developed bradycardia (heart rate $<$ $30 / \mathrm{min}$ ) and subsequently were unresponsive with asystole 15-20 min after spinal anaesthesia without any prodromal symptoms. However, the mechanism that triggers cardiac arrest under spinal anaesthesia remains controversial and unclear. The contribution of intrinsic cardiac mechanisms and autonomic imbalance with the background of parasympathetic predominance might provide a more convincing and physiologic explanation for the occurrence of abrupt severe bradycardia and cardiac arrest under spinal anaesthesia [19, 20]. Furthermore, over sedation, respiratory arrest, unintentional total spinal, myocardial infarction and local anaesthetic toxicity might also attribute to the causative factors [18]. Fully understanding the physiologic changes caused by spinal anaesthesia and its complications, appropriately selecting patients, respecting the contraindications of the procedure, performing adequate monitoring, and exhibiting constant vigilance are particularly important for the eventual outcome $[19,20]$.

In this study, 15 adult patients were in the anaesthesiacontributing group. Most of them were due to cardiovascular events, which was consistent with the reports from the Germany tertiary care university hospital by Hohn et al. [4]. It had been suggested that the mortality for adult anaesthesia-contributing cardiac events was much higher than that for anaesthesia-related cardiac events [3]. Our study showed that the mortality for anaesthesia-contributing cardiac events was $40.0 \%$ (6/15), which was comparable to that of anaesthesia-related cardiac events. This result might be related to the more complicated intraoperative events in these cases that may be caused by anaesthesia, surgery, or other factors.

The limitations of our study are as follows. First, the retrospective nature of the present study is a great limitation; hence, a prospective study will help to clarify the findings. Second, risk factors were only identified from the population of patients undergoing cardiac arrest within $24 \mathrm{~h}$ of surgery. Thus, the present analysis based 
on patients who were likely at risk of cardiac arrest within the 24-h perioperative period may not necessarily be generalized to the entire population of 152,513 patients. Third, the results of the present study were from a single-centre study, which might not be generalizable. We hope to perform a multi-centre prospective survey to reveal the incidence and risk factors for anaesthesia-related cardiac arrest.

\section{Conclusions}

In summary, we found eleven anaesthesia-related cardiac arrest cases of 104 cardiac arrests within $24 \mathrm{~h}$ of anaesthesia administration. Most cardiac arrests related to anaesthesia were due to cardiovascular events, including arrhythmia and hypotension after intravenous narcotic, as well as haemorrhage. In addition, ASA physical status of at least 3 and subarachnoid block appeared to be relevant risk factors for anaesthesia-related cardiac arrest. We hope the results of this study will serve as a basis for national benchmarking.

\section{Abbreviation}

ASA: American Society of Anesthesiologists

\section{Acknowledgements}

We thank Chun Hao, who provided suggestions on the data analysis.

\section{Availability of data and materials}

Reasonable requests for access to the datasets used and/or analysed during the study can be made to the corresponding author.

\section{Authors' contributions}

CLG and JPH carried out the acquisition and interpretation of the data. ZLQ and QQZ performed the statistical analysis. XL was involved in drafting of the manuscript. XL ZQH and SLZ conceived and designed the study and critically revised the manuscript. All authors read and approved the final manuscript.

\section{Ethics approval and consent to participate}

The project was approved by the Research Ethics Committee of the Third Affiliated Hospital of Sun Yat-sen University (Ref: [2017] 2-216). Because of the retrospective and anonymous nature of this study, written informed consent was waived by the Research Ethics Committee of the Third Affiliated Hospital of Sun Yat-sen University.

\section{Consent for publication}

Not applicable

\section{Competing interests}

The authors declare that they have no competing interests.

\section{Publisher's Note}

Springer Nature remains neutral with regard to jurisdictional claims in published maps and institutional affiliations.

Received: 25 April 2018 Accepted: 28 August 2018 Published online: 11 September 2018

\section{References}

1. Weiser TG, Haynes AB, Molina G, et al. Size and distribution of the global volume of surgery in 2012. Bull World Health Organ. 2016;94:201-209F.

2. Bainbridge D, Martin J, Arango M, Cheng D. Evidence-based Peri-operative clinical outcomes research (EPiCOR) group. Perioperative and anaesthetic- related mortality in developed and developing countries: a systematic review and meta-analysis. Lancet. 2012;380:1075-81.

3. Ellis SJ, Newland MC, Simonson JA, et al. Anesthesia-related cardiac arrest. Anesthesiology. 2014;120:829-38.

4. Hohn A, Machatschek JN, Franklin J, Padosch SA. Incidence and risk factors of anaesthesia-related perioperative cardiac arrest: a 6-year observational study from a tertiary care university hospital. Eur J Anaesthesiol. 2018;35:266-72.

5. Murat I, Constant I, Maud'huy H. Perioperative anaesthetic morbidity in children: a database of 24165 anaesthetics over a 30-month period. Pediatr Anesth. 2004;14:158-66.

6. Ahmed A, Ali M, Khan EA, Khan MU. An audit of perioperative cardiac arrests in a southeast Asian university teaching hospital over 15 years. Anaesth Intensive Care. 2008:36:710-6.

7. Messahel FM, Al-Qahtani AS. Incidence of perioperative cardiac arrest: analysis of anesthetics over 18-year period. Middle East J Anaesthesiol. 2010;20:815-9.

8. Braz LG, Módolo NS, do Nascimento $P$, et al. Perioperative cardiac arrest: a study of 53,718 anaesthetics over 9 yr from a Brazilian teaching hospital. $\mathrm{Br}$ Anaesth. 2006;96:569-75.

9. Huo T, Sun L, Min S, et al. Major complications of regional anesthesia in 11 teaching hospitals of China: a prospective survey of 106,569 cases. J Clin Anesth. 2016;31:154-61.

10. Cheney FW, Posner KL, Lee LA, Caplan RA, Domino KB. Trends in anesthesiarelated death and brain damage: a closed claims analysis. Anesthesiology. 2006:105:1081-6.

11. Morray JP, Geiduschek JM, Ramamoorthy C, et al. Anaesthesiarelated cardiac arrest in children: initial findings of the pediatric perioperative cardiac arrest (POCA) registry. Anesthesiology. 2000;93:6-14.

12. Pignaton W, Braz JR, Kusano PS, et al. Perioperative and anesthesia-related mortality: an 8-year observational survey from a tertiary teaching hospital. Medicine (Baltimore). 2016;95:e2208.

13. Schiff JH, Welker A, Fohr B, et al. Major incidents and complications in otherwise healthy patients undergoing elective procedures: results based on 1.37 million anaesthetic procedures. Br J Anaesth. 2014;113:109-21.

14. Bhananker SM1, Ramamoorthy C, Geiduschek JM, et al. Anesthesia-related cardiac arrest in children: update from the pediatric perioperative cardiac arrest registry. Anesth Analg. 2007;105:344-50.

15. Apfelbaum JL, Hagberg CA, Caplan RA, et al. Practice guidelines for management of the difficult airway: an updated report by the American Society of Anesthesiologists Task Force on Management of the Difficult Airway. Anesthesiology. 2013;118:251-70.

16. Nunes JC, Braz JR, Oliveira TS, de Carvalho LR, Castiglia YM, Braz LG. Intraoperative and anesthesia-related cardiac arrest and its mortality in older patients: a 15-year survey in a tertiary teaching hospital. PLoS One. 2014;9:e104041.

17. Bishop MJ, Souders JE, Peterson CM, Henderson WG, Domino KB. Factors associated with unanticipated day of surgery deaths in department of veterans affairs hospitals. Anesth Analg. 2008;107:1924-35.

18. Kopp SL, Horlocker TT, Warner ME, et al. Cardiac arrest during neuraxial anesthesia: frequency and predisposing factors associated with survival. Anesth Analg. 2005;100:855-65.

19. Dyamanna DN, Bs SK, Zacharia BT. Unexpected bradycardia and cardiac arrest under spinal anesthesia: case reports and review of literature. Middle East J Anaesthesiol. 2013;22:121-5.

20. Alegbeleye BJ. Sudden cardiac arrest under spinal anesthesia in a mission hospital: a case report and review of the literature. J Med Case Rep. 2018;12:144.

Ready to submit your research? Choose BMC and benefit from:

- fast, convenient online submission

- thorough peer review by experienced researchers in your field

- rapid publication on acceptance

- support for research data, including large and complex data types

- gold Open Access which fosters wider collaboration and increased citations

- maximum visibility for your research: over $100 \mathrm{M}$ website views per year

At BMC, research is always in progress.

Learn more biomedcentral.com/submission 